\title{
Management of Coronary Artery Disease in the Setting of Transcatheter Aortic Valve Replacement
}

\author{
Natraj Katta, ${ }^{1}$ J Dawn Abbott, ${ }^{2}$ Ankur Kalra, ${ }^{3}$ Fawaz Alenezi, ${ }^{4}$ Andrew Goldsweig, ${ }^{1}$ Herbert Aronow ${ }^{2}$ \\ and Poonam Velagapudi
}

1. University of Nebraska Medical Center, Omaha, NE, USA; 2. Brown University, Providence, RI, USA; 3. Department of Cardiovascular Medicine, Heart and Vascular Institute, Cleveland Clinic, Cleveland, OH, USA; 4. Duke University, Durham, NC, USA

DOI: https://doi.org/10.17925/HI.2020.14.1.24

A ortic stenosis and coronary artery disease (CAD) frequently co-exist, as they share a common pathophysiology and risk factors. Due to lack of randomised controlled trials (RCTS) and exclusion of significant CAD in transcatheter aortic valve replacement (TAVR) trials, the optimal method of revascularisation of CAD in patients undergoing TAVR remains unknown. Observational studies and meta-analyses have shown varied results in outcomes for patients with CAD undergoing TAVR, and no significant difference in post-TAVR outcomes in patients who underwent revascularisation either prior to or during TAVR versus those who did not. However, some observational studies have shown that patients with lower residual SYNTAX score (rSS) post-revascularisation have better outcomes post-TAVR compared to those with higher rSS. RCTs are needed to clearly understand whether revascularisation is beneficial in these patients. Until then, management of CAD in patients undergoing TAVR must be individualised based on discussion with the heart team.

\section{Keywords}

Aortic stenosis (AS), transcatheter aortic valve replacement (TAVR), coronary artery disease (CAD), revascularisation, heart team

Disclosures: J Dawn Abbott has received research grants with no direct compensation from Abbott Vascular, SINOMED, AstraZeneca, Bristol Myers Squibb and Biosensors Research USA Inc. Natraj Katta, Ankur Kalra, Fawaz Alenezi, Andrew Goldsweig, Herbert Aronow and Poonam Velagapudi have no financial or non-financial relationships or activities to declare in relation to this article.

Review Process: Double-blind peer review.

Compliance with Ethics: This study involves a review of the literature and did not involve any studies with human or animal subjects performed by any of the authors.

Authorship: The named authors meet the International Committee of Medical Journal Editors (ICMJE) criteria for authorship of this manuscript, take responsibility for the integrity of the work as a whole, and have given final approval for the version to be published. Access: This article is freely accessible at touchCARDIOLOGY.com (c) Touch Medical Media 2020.

Received: 29 October 2019

Accepted: 6 March 2020

Published Online: 15 April 2020

Citation: Heart International. 2020;14(1):24-8

Corresponding Author: Poonam Velagapudi, University of Nebraska Medical Center, Omaha, NE, USA. E: poonam.velagapudi@unmc.edu, Twitter: @pooh_velagapudi

Support: No funding was received for

the publication of this article.
Individuals with aortic stenosis frequently have coronary artery disease (CAD). ${ }^{1}$ Both conditions share a common pathophysiology involving low-density lipoprotein-mediated inflammatory response, resulting in an accelerated atherosclerotic process. ${ }^{2}$ They also share similar risk factors, such as age, smoking, hypertension, diabetes mellitus, hyperlipidaemia and chronic kidney disease. ${ }^{3,4}$ More than $50 \%$ of patients with severe aortic stenosis undergoing treatment with surgical aortic valve replacement or transcatheter aortic valve replacement (TAVR) have concomitant CAD. ${ }^{5-7}$ Due to a lack of randomised controlled trials (RCTs) and exclusion of significant CAD in TAVR trials, the optimal method of revascularisation of CAD in patients undergoing TAVR remains controversial, with several observational studies and meta-analyses showing conflicting results. ${ }^{6.8-15}$ Nevertheless, current guidelines give a class lla recommendation for percutaneous coronary intervention (PCl) in patients undergoing TAVR with significant CAD involving $>70 \%$ diameter stenosis in a major coronary artery, or $>50 \%$ diameter stenosis in the left main coronary artery. ${ }^{16,17}$

\section{Prevalence of coronary artery disease in transcatheter aortic valve replacement population}

The prevalence of CAD in patients with TAVR varies from 30-80\%. ${ }^{18-25}$ Based on varying definitions of significant CAD, about $50-70 \%$ of patients with aortic stenosis have concomitant significant CAD, ${ }^{6,8,26,27}$ with $50 \%$ having multivessel CAD. ${ }^{10,26,28-30}$ In the FRANCE 2 (FRench Aortic National Corevalve and Edwards 2) registry of 3,195 patients that underwent TAVR, $48 \%$ had CAD, $16 \%$ had history of myocardial infarction and $18 \%$ had prior surgical coronary revascularisation. ${ }^{31}$

\section{Impact of coronary artery disease on transcatheter aortic valve replacement outcomes}

Studies evaluating outcomes of patients undergoing TAVR who also have concomitant CAD have shown conflicting results. Dewey et al. showed significantly higher 30-day and 1-year mortality in patients with history of coronary artery bypass grafting or PCI undergoing TAVR. ${ }^{20} \mathrm{~A}$ meta-analysis by Sankaramangalam et al., which included 15 studies with 8,013 patients, demonstrated that patients with CAD had no difference in 30-day all-cause mortality (odds ratio [OR] 1.07; 95\% confidence interval $[C I]$ 0.82-1.40; $p=0.62$ ), but a significant increase in 1-year all-cause mortality (OR 1.21; $95 \% \mathrm{Cl}$ 1.07-1.36; $p=0.002$ ) post-TAVR, compared to those without CAD. ${ }^{32}$ In contrast, multiple studies have shown no difference in outcomes in patients with or without CAD undergoing TAVR..$^{10,27,33-5}$ In particular, a study by Khawaja et al. showed no difference in 30-day or 1-year mortality in patients with significant CAD who underwent TAVR. ${ }^{10}$ However, patients with a SYNTAX score $>9$ at the time of TAVR had greater 30-day and 1-year mortality compared to those with a score $<9 .{ }^{10}$ Among patients who underwent TAVR, Masson et al. reported no difference in 30-day mortality, 1 -year mortality or left ventricular systolic function recovery between those with and without 
Table 1: Studies comparing outcomes in patients undergoing isolated TAVR versus PCI and TAVR

\begin{tabular}{|c|c|c|c|c|}
\hline Study & Design & $\begin{array}{l}\text { Patients with } \mathrm{PCl} \\
\text { prior to TAVR }\end{array}$ & Isolated TAVR & Clinical outcomes \\
\hline Wenaweser et al. $2011^{6}$ & Single-centre registry & 59 & 197 & No difference in 2-year all-cause mortality \\
\hline Abdel-Wahab et al. $2012^{8}$ & Single-centre registry & 55 & 70 & No difference in 3-year all-cause mortality \\
\hline Ussia et al. $2013^{15}$ & Single-centre registry & 183 & 92 & No difference in 1-year all-cause mortality \\
\hline Abramowitz et al. $2014^{36}$ & Single-centre registry & 61 & 83 & No difference in 3-year all-cause mortality \\
\hline Khawaja et al. $2015^{10}$ & Single-centre registry & 25 & 68 & No difference in 1-year all-cause mortality \\
\hline Snow et al. $2015^{37}$ & Multi-centre registry & 701 & 2,005 & No difference in 5-year all-cause mortality \\
\hline Chakravarty et al. $2016^{9}$ & Multi-centre registry & 128 & 128 & No difference in 1-year all-cause mortality \\
\hline Millan-Iturbe et al. 201811 & Single-centre registry & 136 & 88 & No difference in 9-year all-cause mortality \\
\hline
\end{tabular}

$\mathrm{PCl}=$ percutaneous coronary intervention; TAVR = transcatheter aortic valve replacement .

CAD, classified by Duke Myocardial Jeopardy Score (DMJS). ${ }^{34}$ Chauhan et al. showed, in patients with CAD undergoing TAVR, there was no significant asSociation between SYNTAX or DMJS and primary composite endpoint of postoperative coronary revascularisation, all-cause mortality and major adverse cardiovascular and cerebrovascular events (MACCE). ${ }^{33}$ A meta-analysis by D'Ascenzo et al., which included data from seven observational studies, showed no difference in all-cause mortality in patients with and without CAD undergoing TAVR. ${ }^{35}$

\section{Impact of coronary revascularisation on transcatheter aortic valve replacement outcomes}

The RCTs of TAVR excluded patients with severe CAD. ${ }^{18,20-5}$ There are no RCTs evaluating outcomes of coronary revascularisation before or during TAVR in patients with concomitant CAD, and several observational studies and meta-analyses have reported conflicting results. $6,8-15,30,3,37$ Multiple single-centre registries showed no difference in mortality in follow-up up to 5 years in patients that underwent PCI prior to TAVR versus TAVR alone (Table 1). $6.8-11,1,5,36,37$

A meta-analysis by Kotronias et al., including nine studies with 3,858 patients, showed that patients with CAD who underwent revascularisation prior to TAVR had a higher rate of vascular complications (OR 1.86; 95\% Cl 1.33-2.60; $\mathrm{p}=0.0003$ ) and all-cause mortality (OR 1.42; $95 \% \mathrm{Cl} 1.08-1.87 ; \mathrm{p}=0.01)$ at 30 days with no difference in cardiovascular mortality, myocardial infarction, acute kidney injury or 1-year mortality. ${ }^{26}$ A more recent meta-analysis by Lateef et al., including 11 studies with 5,580 patients, found no difference in 30-day all-cause mortality (OR 1.30; 95\% Cl 0.85-1.98; $\mathrm{p}=0.22)$, stroke (OR $0.7 ; 95 \% \mathrm{Cl} 0.36-1.45 ; \mathrm{p}=0.36)$, myocardial infarction (OR 2.71; $95 \% \mathrm{Cl} 0.55-12.23 ; \mathrm{p}=0.22$ ), acute kidney injury ( $\mathrm{OR} \quad 0.7 ; 95 \% \mathrm{Cl} 0.46-1.06 ; \mathrm{p}=0.08$ ) or 1 -year all-cause mortality (OR 1.19; 95\% $\mathrm{Cl} 0.92-1.52 ; \mathrm{p}=0.18$ ) in patients who underwent TAVR with and without $\mathrm{PCl}^{38}$ Overall, the impact of coronary revascularisation in patients with concomitant severe aortic stenosis is a subject of ongoing debate.

\section{Ischaemia evaluation in patients with concomitant coronary artery disease and aortic stenosis}

\section{Non-invasive stress testing}

In patients with severe aortic stenosis and concomitant CAD, the identification of ischaemia secondary to $C A D$ can be challenging as aortic stenosis causes myocardial ischaemia on stress testing in the absence of angiographically significant $C A D$, which generally tends to disappear after valve replacement. ${ }^{39}$ Hence, non-invasive stress testing has lower sensitivity and specificity for detecting CAD in severe aortic stenosis patients. ${ }^{39,40}$ There are no data to support the use of non-invasive assessment to guide revascularisation in patients undergoing TAVR. However, non-invasive stress testing can be helpful if the area of ischaemic myocardium matches the territory subtended by the stenosed coronary artery.

\section{Invasive coronary functional assessment}

Although fractional flow reserve (FFR) and instantaneous wave-free ratio (iFR) are standard methods of invasive physiologic assessment of CAD, there is significant ambiguity interpreting these results in patients with severe aortic stenosis. ${ }^{41}$ This is due to the unequal changes on proximal pressure waveforms caused by stenosed aortic valve, the haemodynamic effect of the uncoupling of aortic valve closure from a decrease in left ventricular pressure, and the effect of left ventricular hypertrophy on microvascular function. ${ }^{42}$ However, a recent study by Ahmad et al. showed iFR values did not change pre- and post-TAVR $(p=0.73)$, whereas FFR decreased significantly post-TAVR compared with pre-TAVR $(p=0.001)$, indicating iFR may be reliable in identifying significant CAD.43

\section{Impact of extent of revascularisation on transcatheter aortic valve replacement outcomes}

Though there are no RCTs in this sphere, there are several observational studies and meta-analyses that evaluated the effect of completeness of revascularisation on post-TAVR outcomes. The residual SYNTAX score (rSS) is an objective measure of the degree and complexity of residual CAD after $\mathrm{PCl}$, and is a powerful indicator of 5-year mortality. ${ }^{44}$ Recent single-centre registry data showed that patients who underwent $\mathrm{PCl}$ prior to TAVR and had low rSS, ranging from 0-14, had a lower incidence of MACCE over 5 years of follow-up when compared with high rSS. ${ }^{12-14,30} \mathrm{~A}$ meta-analysis by D'Ascenzo et al., which included 13 studies and 8,334 patients, showed mere presence of CAD had no effect on 30-day or 1-year mortality in patients who underwent TAVR, but those patients with CAD and SYNTAX score $>22$ had higher 1-year mortality (OR 1.71; 95\% Cl 1.24-2.36) and those with a rSS <8 post-PCI had lower 1-year mortality (OR 0.34; 95\% Cl 0.012-0.93). ${ }^{28}$ Witberg et al. showed that patients with a SYNTAX score $>22$ had higher MACCE up to 2 years after TAVR, and patients with rSS $<8$ had similar MACCE compared to patients without CAD. ${ }^{45}$ In another study, Witberg et al. compared the effect of severity of CAD and complete versus incomplete revascularisation (rSS >8) on TAVR outcomes, and showed higher all-cause mortality at 1.9 years in patients with SYNTAX score $>22$ (hazard ratio [HR] 2.091; $\mathrm{p}=0.017)$ and incomplete revascularisation $(\mathrm{rSS}>8)(\mathrm{HR} 1.720 ; \mathrm{p}=0.031) .{ }^{30}$ 
Table 2: Summary of studies evaluating the impact of post-PCI residual SYNTAX score on TAVR outcomes

\begin{tabular}{|c|c|c|c|c|}
\hline Study & Design & $\begin{array}{l}\text { Patients with low } \\
\text { and high rSS (n) }\end{array}$ & rSS cut-off & Clinical outcomes \\
\hline Stefanini et al. $2014^{14}$ & Single-centre registry & $\begin{array}{l}\text { Low rSS }=192 \\
\text { High rSS }=95\end{array}$ & 14 & High rSS is associated with increased risk of 1-year MACCE after TAVR \\
\hline Khawaja et al. $2015^{10}$ & Single-centre registry & $\begin{array}{l}\text { Low rSS }=40 \\
\text { High rSS }=53\end{array}$ & 9 & High rSS is associated with increased 1-year MACCE after TAVR \\
\hline Paradis et al. $2017^{12}$ & Single-centre registry & $\begin{array}{l}\text { Low rSS }=17 \\
\text { High rSS }=37\end{array}$ & 8 & High rSS is not associated with increased 1-year MACCE after TAVR \\
\hline Shamekhi et al. $2017^{13}$ & Single-centre registry & $\begin{array}{l}\text { Low rSS }=140 \\
\text { High rSS }=205\end{array}$ & 3 & High rSS is associated with increased 3-year mortality after TAVR \\
\hline Witberg et al. $2017^{30}$ & Multi-centre registry & $\begin{array}{l}\text { Low rSS }=331 \\
\text { High rSS }=122\end{array}$ & 8 & High rSS is associated with increased 5-year mortality after TAVR \\
\hline
\end{tabular}

MACCE = major adverse cardiovascular and cerebrovascular events; $P C I=$ percutaneous coronary intervention; $r$ SS = residual SYNTAX SCOre; TAVR = tranSCatheter aortic valve replacement.

A meta-analysis by Witberg et al. including 3,107 patients from six studies with 0.7-3.0 years of follow-up showed that in patients with SYNTAX score $>22$, incomplete revascularisation with $\mathrm{rSS}>8$ was associated with an increased risk for mortality when compared with patients with no CAD (OR 1.85; 1.42-2.40; $p<0.01$ ) or those with revascularisation and rSS $<8$ (OR 1.69; 1.26-2.28; $p<0.001$ ), or to both groups combined (OR 1.71; 1.36-2.16; $\mathrm{p}<0.001) .{ }^{46}$ Table 2 summarises studies evaluating impact of post-PCI rSS on TAVR outcomes.

Thus, SYNTAX score could be used as a tool to help guide revascularisation prior to TAVR, and one may aim to achieve an rSS $<8$ with revascularisation for best outcomes post-TAVR. However, the findings of observational studies related to the effect of SYNTAX score and rSS on TAVR outcomes need to be confirmed in RCTs for their use to be incorporated into guidelines and routine practice. Figure 1 depicts our proposed algorithm for revascularisation in patients undergoing TAVR.

\section{Timing of coronary revascularisation in transcatheter aortic valve replacement}

The optimal timing of coronary revascularisation in relation to TAVR is unknown due to conflicting findings of observational studies and lack of RCTs. Although revascularisation prior to TAVR is a widely practiced approach, combining TAVR and revascularisation as a single procedure has been previously studied.

Conradi et al. showed the feasibility of performing revascularisation and TAVR as a combined procedure. ${ }^{47}$ Among 28 patients who were deemed not candidates for surgery, 21 patients underwent a two-stage approach of revascularisation prior to TAVR and the remaining seven patients underwent revascularisation followed by TAVR in a single-stage procedure. Thirty-day mortality (4.8\% versus $14.3 \%$ ), fluoroscopy time and contrast volume were higher with a single-stage procedure compared to a two-stage approach with no occurrence of peri-procedural myocardial infarction or stroke in either group. ${ }^{47}$ Wenaweser et al. compared outcomes among patients who underwent revascularisation and TAVR as concomitant procedures, revascularisation prior to TAVR in a two-stage procedure, or TAVR alone, and noted no significant difference in 30-day mortality between concomitant TAVR and revascularisation compared to the other two groups $(11.1 \%, 8.7 \%$ and $5.6 \%$, respectively; $\mathrm{p}=0.24) .{ }^{6}$ A study by Pasic et al. showed combining TAVR and revascularisation as a single procedure had a 30-day mortality of $4.3 \%$ with no increased risk of renal failure, although lack of a control arm was a limitation in this study. ${ }^{48}$
Figure 1: Proposed algorithm for revascularisation in patients with severe aortic stenosis and concomitant CAD undergoing TAVR

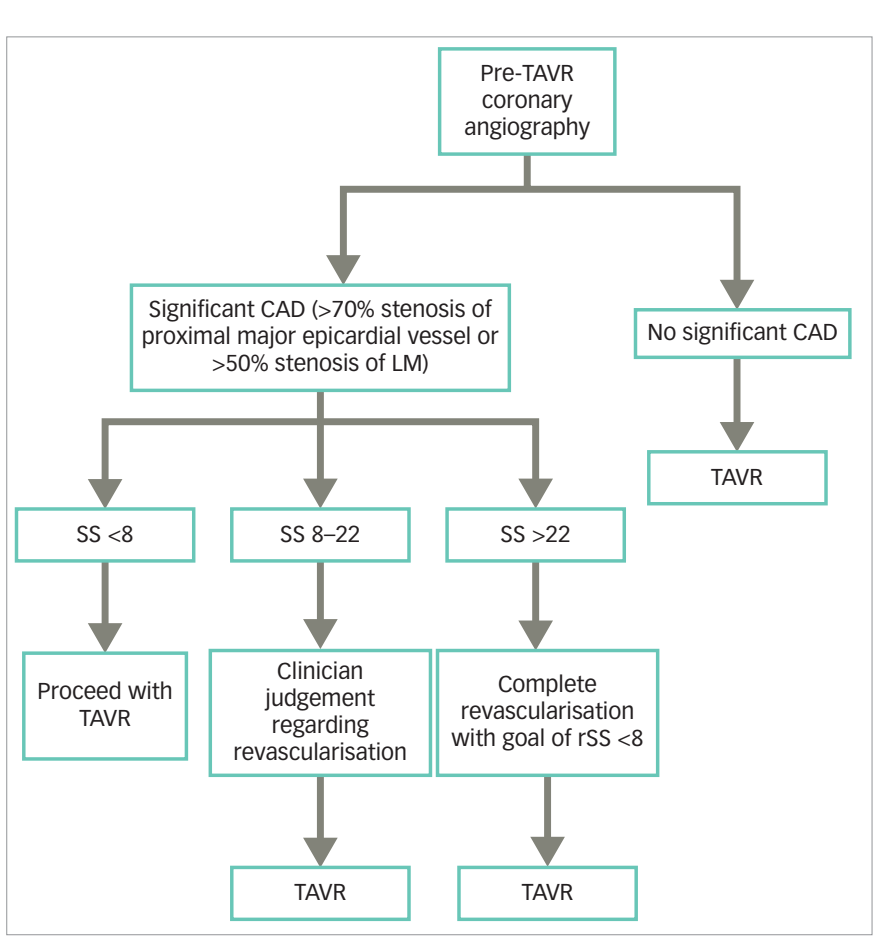

$C A D=$ coronary artery disease $;$ LM = left main; $S S$ = SYNTAX score $r S S=$ residual SYNTAX Score; TAVR = transcatheter aortic valve replacement.

Although there are potential benefits of combining TAVR and revascularisation as a single procedure, such as fewer vascular access procedures and reduction in ischaemic burden during TAVR, there is a potential increased risk of contrast-induced nephropathy as well as increased operator and patient radiation exposure. Thus, there is a need for RCTs to better understand the optimal timing for revascularisation in relation to TAVR. A more widely practiced strategy is performing revascularisation prior to TAVR. The potential benefits of this approach include easier coronary access in the absence of a valvular prosthesis, lower ischaemic burden and related haemodynamic instability during TAVR, and lower contrast volume and radiation exposure time during each individual procedure. The potential risks include a higher risk of bleeding as these patients are on uninterrupted dual antiplatelet therapy during TAVR, and increased risk of haemodynamic instability 
during revascularisation in the presence of severe aortic stenosis. Abdel-Wahab et al. compared the outcomes of revascularisation followed by TAVR (55 patients) versus isolated TAVR (70 patients).? The median duration from revascularisation to TAVR was 10 days (range 0-90 days), and this small study showed a trend toward lower 30-day mortality with revascularisation prior to TAVR versus TAVR alone ( $2 \%$ versus $6 \%$ respectively, $p=0.27$ ) that did not reach statistical significance.

Revascularisation in patients with left ventricular dysfunction and severe aortic stenosis is challenging as there is risk of haemodynamic instability during the procedure. Goel et al. studied 254 patients with severe aortic stenosis who underwent $\mathrm{PCl} .{ }^{29}$ The results concluded that patients with severe aortic stenosis and low ejection fraction $\leq 30 \%$ had a higher 30-day post- $\mathrm{PCl}$ mortality compared with those with an ejection fraction $>30 \%$ $(5.4 \%$ versus $1.2 \%$, respectively; $p<0.001)$. The study also concluded that a high Society of Thoracic Surgeons (STS) score $\geq 10$ was associated with higher 30-day post-PCI mortality compared with an STS score $<10(10.4 \%$ versus $0 \%$, respectively; $p<0.001$ ). Mechanical circulatory support with Impella ${ }^{\circledast}$ (Abiomed, Danvers, MA, USA) in selected high-risk patients, such as cardiogenic shock or severely depressed ejection fraction, is a feasible option to maintain haemodynamic stability in patients with severe aortic stenosis undergoing $\mathrm{PCl} .{ }^{49,50} \mathrm{~A}$ recent publication from the Catheter-based ventricular assist devices (CVAD) registry, including 116 patients (mean STS score $18.7 \pm 18.3 \%$, mean left ventricular ejection fraction $27 \pm 16 \%$, and mean aortic valve area $0.67 \pm 0.29 \mathrm{~cm}^{2}$ ) who received high-risk $\mathrm{PCl}$ and Impella-assisted balloon-assisted valvuloplasty, demonstrated that elective Impella support was associated with higher 1-year survival compared with rescue placement. ${ }^{50}$ However, RCT data are currently lacking and needed for identifying the best management option in these high-risk patients.

With conflicting results from observational studies and meta-analyses, the dilemma of whether to perform revascularisation plus TAVR or TAVR alone, remains. Three ongoing RCTs will help answer this question: the ACTIVATION trial (ISRCTN75836930) is a prospective RCT that compares $\mathrm{PCl}$ in coronary arteries with more than $70 \%$ stenosis followed by TAVR versus TAVR alone; ${ }^{51}$ NOTION-3 (NCT03058627) is a prospective RCT comparing TAVR alone versus FFR-guided PCI plus TAVR; and the FAITAV trial (NCT03360591) is a prospective RCT comparing angiographic- versus FFR-guided PCl in patients undergoing TAVR.

\section{Challenges of coronary revascularisation post-transcatheter aortic valve replacement}

Coronary access and $\mathrm{PCl}$ may be challenging in patients post-TAVR It is important to understand the structure of each transcatheter aortic valve prosthesis for optimal success. Pre-procedure computed tomography analysis is critical for TAVR procedure planning, in order to avoid coronary obstruction. ${ }^{52,53}$ A large observational study by Zivelonghi et al. showed coronary re-access and $\mathrm{PCl}$ are possible after TAVR. $^{54}$ The authors performed coronary angiograms after TAVR in 66 patients: 25 with Corevalve ${ }^{\mathrm{TM}}$ Evolut' ${ }^{\mathrm{TM}} \mathrm{R}$ System transcatheter aortic valves (Medtronic, Dublin, Ireland) and 41 with SAPIEN 3 valves (Edwards Lifesciences, Irvine, CA, USA). They successfully performed diagnostic angiography with diagnostic catheters in $96 \%$ of vessels; $4 \%$ of vessels required guide catheters, while one artery could not be engaged due to the unfavourable positioning of an Evolut R valve. ${ }^{54}$ They were able to successfully perform $\mathrm{PCl}$ in all 17 intended patients: 6 with Evolut $\mathrm{R}$ and 11 with SAPIEN 3 valves. ${ }^{54}$

Coronary re-engagement may be especially challenging with self-expanding Evolut R valves, as the valve extends above the coronary ostia, unlike the balloon-expandable SAPIEN 3. ${ }^{53}$ However, these challenges may be overcome with increased operator experience and down-sizing of the catheter. According to a study by Boukantar et al., among patients with Evolut R valves, post-TAVR PCI was associated with significantly higher contrast usage, fluoroscopy times and radiation dosage when compared with coronary angiography performed prior to TAVR. ${ }^{55}$ Aortic stenosis indications for TAVR have recently expanded to include a lower risk population; younger patients may undergo TAVR, necessitating more frequent post-TAVR coronary procedures. Moreover, a wide variety of TAVR valves have emerged into clinical practice, including the self-expanding Jenavalve ${ }^{\mathrm{TM}}$ (Jenavalve Technology GmbH, Munich, Germany), the Portico'M valve (St. Jude Medical, MN, USA), the ACURATE neo ${ }^{\mathrm{TM}}$ Aortic Valve System (Boston Scientific, Marlborough, MA, USA), the LOTUS Edge ${ }^{\mathrm{TM}}$ Aortic Valve System (Boston Scientific), and the Allegra transcatheter aortic valve (NVT AG, Muri, Switzerland), that necessitate interventional cardiologists to become proficient in post-TAVR angiography and $\mathrm{PCl}$ with each different valve.

\section{Conclusion}

In summary, in patients with CAD undergoing TAVR, the SYNTAX score can be a useful tool in deciding which patients may benefit from PCl prior to TAVR. In patients with high SYNTAX score (>22), we recommend performing PCI before TAVR to improve post-TAVR outcomes. In those with low SYNTAX score $(<8)$, no additional coronary intervention is necessary and operators can proceed directly with TAVR. However, in those with intermediate SYNTAX score (8-22), the decision to perform $\mathrm{PCl}$ should be individualised based on the clinical risk factors in consultation with the heart team. Further large-scale RCTs are required to provide definitive answers regarding management of these complex groups of patients.
1. Otto CM, Lind BK, Kitzman DW, et al. Association of aortic-valve sclerosis with cardiovascular mortality and morbidity in the elderly. N Engl J Med. 1999;341:142-7.

2. Otto CM, Kuusisto J, Reichenbach DD, et al. Characterization of the early lesion of 'degenerative' valvular aortic stenosis. Histological and immunohistochemical studies. Circulation. 1994;90:844-53.

3. Deutscher S, Rockette HE, Krishnaswami V. Diabetes and hypercholesterolemia among patients with calcific aortic stenosis. J Chronic Dis. 1984;37:407-15.

4. Mohler ER, Sheridan MJ, Nichols R, et al. Development and Mrohler ER, Sheridan MJ, Nichols R, et al. Development and progression of aortic valve stenosis: atherosclerosis risk flin Cardiol. 1991:14:995-9.

Clin Cardiol. 1991;14:995-9.
Beach JM, Mihaljevic T, Svensson LG, et al. Coronary artery Beach JM, Mihaljevic T, Svensson LG, et al. Coronary artery
disease and outcomes of aortic valve replacement for severe disease and outcomes of aortic valve replacement
aortic stenosis. J Am Coll Cardiol. 2013;61:837-48.

6. Wenaweser P, Pilgrim T, Guerios E, et al. Impact of coronary artery disease and percutaneous coronary intervention on outcomes in patients with severe aortic stenosis undergoing transcatheter aortic valve implantation. Eurolntervention. 2011;7:541-8.

Abdel-Wahab M, Zahn R, Horack M, et al. Transcatheter aortic valve implantation in patients with and without concomitant coronary artery disease: comparison of characteristics and early outcome in the German multicentre TAVI registry. Clin Res Cardiol. 2012;101:973-81.

8. Abdel-Wahab M, Mostafa AE, Geist V, et al. Comparison of outcomes in patients having isolated transcatheter aortic valve implantation versus combined with preprocedural percutaneous coronary intervention. Am J Cardiol. 2012;109:581-6.

9. Chakravarty T, Sharma R, Abramowitz Y, et al. Outcomes in patients with transcatheter aortic valve replacement and left main stenting: the TAVR-LM Registry. J Am Coll Cardiol. 2016;67:951-60

10. Khawaja MZ, Asrress KN, Haran $\mathrm{H}$, et al. The effect of coronary artery disease defined by quantitative coronary angiography artery disease defined by quantitative coronary angiography
and SYNTAX score upon outcome after transcatheter aortic and SYNTAX score upon outcome after transcatheter aortic valve implantation (TAVI) using the Edwards bioprosthesis. Eurolntervention. 2015;11:450-5.

11. Millan-Iturbe O, Sawaya FJ, Lonborg J, et al. Coronary artery disease, revascularization, and clinical outcomes in transcatheter aortic valve replacement: Real-world results from the East Denmark Heart Registry. Catheter Cardiovasc Interv. 2018;92:818-26

12. Paradis JM, White JM, GenereuX $\mathrm{P}$, et al. Impact of coronary artery disease severity assessed with the SYNTAX score on outcomes following transcatheter aortic valve replacement. J Am Heart Assoc. 2017;6:e005070.

13. Shamekhi J, Stundl A, Weber M, et al. Impact of coronary artery disease in patients undergoing transfemoral transcatheter aortic valve implantation. Int I Cardiol. 2017;245:215-21

14. Stefanini GG, Stortecky S, Cao D, et al. Coronary artery disease severity and aortic stenosis: clinical outcomes according to SYNTAX score in patients undergoing accora 2014;35:2530-40

15. Ussia GP, Barbanti M, Colombo A, et al. Impact of coronary artery disease in elderly patients undergoing transcatheter aortic valve implantation: insight from the Italian Corevalve Registry. Int J Cardiol. 2013;167:943-50.

16. Baumgartner H, Falk V, Bax JJ, et al. 2017 ESC/EACTS Guidelines for the management of valvular heart disease. Eur Heart $\mathrm{J}$. 2017;38:2739-91.

17. Nishimura RA, Otto CM, Bonow RO, et al. 2014 AHA/ACC guideline for the management of patients with valvular heart disease: a report of the American College of Cardiology/ American Heart Association Task Force on Practice Guidelines. J Thorac Cardiovasc Surg. 2014;148:e1-132. 
18. Adams DH, Popma JJ, Reardon MJ, et al. Transcatheter aortic-valve replacement with a self-expanding prosthesis. N Engl J Med. 2014:370:1790-8.

19. Feldman TE, Reardon MJ, Rajagopal V, et al. Effect of mechanically expanded vs self-expanding transcatheter aortic valve replacement on mortality and major adverse clinical events in high-risk patients with aortic stenosis: The REPRISE II randomized clinical trial. JAMA. 2018;319:27-37.

20. Dewey TM, Brown DL, Herbert MA, et al. Effect of concomitant coronary artery disease on procedural and late outcomes of transcatheter aortic valve implantation. Ann Thorac Surg. 2010;89:758-67.

21. Smith $\mathrm{CR}$, Leon $\mathrm{MB}$, Mack MJ, et al. Transcatheter versus surgical aortic-valve replacement in high-risk patients. N Eng/ J Med. 2011;364:2187-98.

22. Leon MB, Smith CR, Mack MJ, et al. Transcatheter or surgical aortic-valve replacement in intermediate-risk patients. N Eng Med 2016:374:1609-20.

23. Mack MJ, Leon MB, Thourani VH, et al. Transcatheter aortic-valve replacement with a balloon-expandable valve in low-risk patients. N Engl J Med. 2019;380:1695-705.

24. Popma JJ, Deeb GM, Yakubov SJ, et al. Transcatheter aortic-valve replacement with a self-expanding valve in low-risk patients. N Eng/ J Med. 2019;380:1706-15.

25. Reardon MJ, Van Mieghem NM, Popma JJ, et al. Surgical or transcatheter aortic-valve replacement in intermediate-risk patients. N Eng/ J Med. 2017;376:1321-31.

26. Kotronias RA, Kwok CS, George S, et al. Transcatheter aortic valve implantation with or without percutaneous coronary artery revascularization strategy: a systematic review and meta-analysis. J Am Heart Assoc. 2017;6:e005960

27. Gautier M, Pepin M, Himbert $D$, et al. Impact of coronary artery disease on indications for transcatheter aortic valve implantation and on procedural outcomes. Eurolntervention. 2011;7:549-55.

28. D'Ascenzo F Verardi $R$, Visconti $M$, et al. Independent impact of extent of coronary artery disease and percutaneous revascularisation on 30-day and one-year mortality after TAVI: a meta-analysis of adjusted observational results. TAVI: a meta-analysis of adjusted obsen
Eurolntervention 2018:14:e1169-77.

29. Goel SS, Agarwal S, Tuzcu EM, et al. Percutaneous coronary intervention in patients with severe aortic stenosis: implications for transcatheter aortic valve replacemen Circulation. 2012;125:1005-13.

30. Witberg G, Regev E, Chen S, et al. The prognostic effects of coronary disease severity and completeness of revascularization on mortality in patients undergoing transcatheter aortic valve replacement. JACC CardiovasC Interv. 2017:10:1428-35.

31. Gilard $\mathrm{M}$, Eltchaninoff $\mathrm{H}$, lung $\mathrm{B}$, et al. Registry of transcathete artic-valve implantation in high-risk patients. N Eng/ J Med. 2012;366:1705-15

32. Sankaramangalam $\mathrm{K}$, Baneriee $\mathrm{K}$, Kandregula $\mathrm{K}$, et al. Impact of coronary artery disease on 30-day and 1-year mortality in patients undergoing transcatheter aortic valve replacement: meta-analysis. J Am Heart Assoc. 2017;6:e006092.

33. Chauhan D, Thawabi M, Haik N, et al. Impact of coronary artery disease on postoperative outcomes in patients undergoing transcatheter aortic valve replacement (TAVR): is preoperative coronary revazcularisation necessary? I Invasive Cardiol. 2016;28:E179-84

34. Masson J-B, Lee M, Boone RH, et al. Impact of coronary artery disease on outcomes after transcatheter aortic valve implantation. Catheter Cardiovasc Interv. 2010;76:165-73.

35. D'Ascenzo F, Conrotto F, Giordana F, et al. Mid-term prognostic value of coronary artery disease in patients undergoing transcatheter aortic valve implantation: A meta-analysis of

adjusted observational results int

Abramowitz Y, Banai S, Katz G, et al. Comparison of early and late outcomes of TAVl alone compared to TAVI plus PCl in ao stenosis patients with and without coronary
Catheter Cardiovasc Interv. 2014:83:649-54.

37. Snow TM, Ludman P, Banya W, et al. Management of concomitant coronary artery disease in patients undergoing transcatheter aortic valve implantation: the United Kingdom TAVI Registry. Int J Cardiol. 2015;199:253-60

38. Lateef $\mathrm{N}$, Khan MS, Deo SV, et al. Meta-analysis comparing outcomes in patients undergoing transcatheter aortic valve implantation with versus without percutaneous coronary intervention. Am J Cardiol. 2019;124:1757-64.

39. Danson E, Hansen P, Sen S, et al. Assessment, treatment, and prognostic implications of CAD in patients undergoing TAVI. Nat Rev Cardiol. 2016;13:276-85.

40. Demirkol MO, Yaymaci B, Debes H, et al. Dipyridamole myocardial perfusion tomography in patients with severe aortic stenosis. Cardiology. 2002;97:37-42.

41. van Nunen LX, Zimmermann FM, Tonino PA, et al. Fractional flow reserve versus angiography for guidance of $\mathrm{PCl}$ in patients with multivessel coronary artery disease (FAME) 5-year follow-up of a randomised controlled trial. Lancet. 2015;386:1853-60.

42. Lumley M, Williams R, Asrress KN, et al. Coronary physiology during exercise and vasodilation in the healthy heart and in severe aortic stenosis. J Am Coll Cardiol. 2016;68:688-97.

43. Ahmad Y, Götberg M, Cook C, et al. Coronary hemodynamics in patients with severe aortic stenosis and coronary artery disease undergoing transcatheter aortic valve replacement JACC Cardiovasc Interv. 2018:11:2019-31.

44. Faroog V Serruys PW, Bourantas CV, et al. Quantification of incomplete revascularisation and its association with five-year mortality in the synergy between percutaneous coronary intervention with taxus and cardiac surgery (SYNTAX) trial validation of the residual SYNTAX score. Circulation. 2013;128:141-51.

45. Witberg G, Lavi I, Harari E, et al. Effect of coronary artery disease severity and revascularisation completeness on 2-yea clinical outcomes in patients undergoing transcatether aortic valve replacement. Coron Artery Dis. 2015;26:573-82.

46. Witberg G, Zusman $\mathrm{O}$, Codner P, et al. Impact of coronary artery revascularisation completeness on outcomes of patients with coronary artery disease undergoing transcatheter aortic valve replacement: a meta-analysis of studies using the residual SYNTAX score (synergy between $\mathrm{PCl}$ with taxus and cardiac surgery). Circ Cardiovasc Intery. 2018;11:e006000.

47. Conradi L, Seiffert M, Franzen O, et al. First experience with transcatheter aortic valve implantation and concomitan percutaneous coronary intervention. Clin Res Cardiol. 2011:100:311-6.

48. Pasic M, Dreysse $S$, Unbehaun $A$, et al. Combined elective percutaneous coronary intervention and transapical transcatheter aortic valve implantation. Interact Cardiovasc Thorac Surg. 2012;14:463-8.

49. Singh V, Mendirichaga R, Inglessis-Azuaje I, et al. The role of Impella for hemodynamic support in patients with aortic stenosis. Curr Treat Options Cardiovasc Med. 2018;20:44.

50. Singh V, Yadav PK, Eng MH, et al. Outcomes of hemodynamic support with Impella in very high-risk patients undergoing balloon aortic valvuloplasty: Results from the Global CVAD Registry. Int J Cardiol. 2017;240:120-5.

51. Khawaja MZ, Wang D, Pocock S, et al. The percutaneous coronary intervention prior to transcatheter aortic valve implantation (ACTIVATION) trial: study protocol for a rendomized controlled trial. Tials. 2014:15:300.

52. Perez S, Thielhelm TP, cohen MG. To revascularize or not before transcatheter aortic valve implantation? I Thorac Dis. 2018; 10:S3578-87.

53. Yudi MB, Sharma SK, Tang GHL, Kini A. Coronary angiography and percutaneous coronary intervention after transcatheter aortic valve replacement. J Am Coll Cardiol. 2018;71:1360-78.

54. Zivelonghi C, Pesarini G, Scarsini R, et al. Coronary catheterization and percutaneous interventions after transcatheter aortic valve implantation. Am J Cardiol. 2017;120:625-31

55. Boukantar M, Gallet R, Mouillet G, et al. Coronary procedures after TAVI with the self-expanding aortic bioprosthesis medtronic corevalve, not an easy matter. I Interv Cardiol. 2017;30:56-62. 